\title{
A Cause of Fever that should be Kept in Mind in Family Medicine in Settlements Where Livestock Farming is Widespread: Brucellosis
}

\author{
(D) Çiğdem El1, (1) Mehmet Emin Çelikkaya² \\ ${ }^{1}$ Hatay Mustafa Kemal University Faculty of Medicine, Department of Pediatrics, Hatay, Turkey \\ ${ }^{2}$ Hatay Mustafa Kemal University Faculty of Medicine, Department of Pediatric Surgery, Hatay, Turkey
}

\begin{abstract}
Aim: In our country, where animal husbandry is widespread, we aimed to examine retrospectively data concerning childhood Brucellosis cases, which are not very high in the literature, which may occur with many variable clinical findings and may cause misdiagnosis and serious complications.

Materials and Methods: The data of these patients with the diagnosis of Brucellosis who were treated between October 2016 and October 2018 in a Pediatric Clinic were retrospectively analyzed. For the diagnosis of Brucellosis in patients, the Wright agglutination test with complaints and clinical findings set at the titer being $1 / 160$ or above was used.

Results: In our study, the mean age of the patients was 7.4 years (3-15). 52.12\% ( $n=37)$ were male and $47.88 \%(n=34)$ were female. All patients had a risk factor for Brucellosis infection. In $88.7 \%$ ( $n=63$ ) of these patients, consumption of milk and dairy products (precipitates, fresh cheese was not cooked), and $11.3 \%(n=8)$ of raw meat (raw meatball) consumption and animal contact history were determined.

Conclusion: Although early diagnosis and response to treatment with Brucellosis are very good, late diagnosis and inadequate treatment may cause mortality and morbidity with serious complications. Complaints of fatigue, weight loss and especially joint pain with long term fever should be evaluated by family physicians and pediatricians. The diagnosis of these patients should be kept in mind in the diagnosis of Brucellosis, an endemic disease common in our country.
\end{abstract}

Keywords: Brucellosis, child, fever

\section{Introduction}

Brucellosis is one of the zoonotic infectious diseases especially in developing countries, and it is still a significant public health problem worldwide (1). According to the data of the Ministry of Health in 2006, 10.810 cases with Brucellosis were detected in Turkey (2). Brucellosis is primarily a disease of animals, but it is also seen in humans living in settlements where animal husbandry is common. Transmission of Brucella species to humans; during the care and butchering of infected animals occurs by contact with the skin or by the consumption of the uncooked or undercooked meat or milk of these animals $(1,3)$. Differential diagnosis is very important due to complaints and clinical findings of Brucellosis not being specific. The disease may present with variable clinical presentations especially in children, and usually begins 
with nonspecific symptoms after a 1-8 week incubation period $(1,4)$. This situation may lead to late diagnoses and various complications $(4,5)$.

Despite the variety clinical findings of Brucellosis, the most common clinical symptoms are fever $(72.2-93.3 \%$, ), arthralgia/arthritis (46.6-73.7\%), hepatosplenomegaly (6.7$20.6 \%)$. Other symptoms include abdominal pain, vomiting, headache, diarrhea, skin rash, night sweats, weakness, fatigue, weight loss, cough, pharyngitis and myalgia (6). The definitive diagnosis of the disease is made by producing the bacteria in culture (blood, bone marrow, cerebrospinal fluid). However, generally in the diagnosis of the disease, a serum agglutination test is used in clinical practice, the diagnosis is made if serum titer of the Brucella is 1/160 or above in this test (4,7-9). However, a delay in diagnosis and treatment, misdiagnosis and serious complications (neurobrucellosis, genitourinary complications, hematological findings, spondylitis, infectious endocarditis and encephalitis even death) may seen in the childhood period because of nonspecific symptoms of the disease.

The Brucellosis series in childhood period have not been reported commonly in the literature. The aim of this study is to retrospectively assess the data of our Brucellossis cases in childhood.

\section{Materials and Methods}

The data of 71 patients who were given a diagnosis of Brucellosis and were treated between October 2016 and October 2018 at the Faculty of Medicine, Department of Pediatrics, were retrospectively reviewed.

The diagnosis of Brucellosis was based on the complaints of the patients, clinical findings and Wright agglutination titer of $1 / 160$ or above.

The medical data from the hospital medical records of risk factors of Brucella transmission (uncooked meat, milk and milk products consumption), demographic data, seasonal distribution, complaints of patients, time to diagnosis from onset of complaints, clinical and laboratory findings, family history were obtained.

Complete blood counts, erythrocyte sedimentation rate (ESR) and C-reactive protein (CRP) values, liver function tests, renal function tests and Wright agglutination test results were evaluated.

It was accepted that a hemoglobin levels below $10 \mathrm{gr} / \mathrm{dL}$ is anemia, a leukocyte level below $3.500 / \mathrm{mm}^{3}$ is leukopenia, above $10.000 / \mathrm{mm}^{3}$ is leukocytosis, a platelet value below $150.000 / \mathrm{mm}^{3}$ is thrombocytopenia, below $20.000 / \mathrm{mm}^{3}$ is severe thrombocytopenia (1).
Patients with chronic disease or immunodeficiency were excluded from the study.

This study was approved by Ethics Board of Mustafa Kemal University (approval number: 08/2018). All of the parents of the patients gave their informed consent prior to their child's inclusion in the study.

\section{Statistical Analysis}

The data was entered into the SPSS 20.00 program (SPSS Inc., Chicago, IL, USA,). Data was presented as percentage with minimum and maximum. Fisher's exact test or chi square test was used to compare between categorical variables groups. Mann-Whitney $U$ test was used to compare continuous variables between groups. P level of $<0.05$ was accepted statistically significant.

\section{Results}

The mean age of the patients in our study was 7.4 years (between 3-15). 52.12\% ( $n=37)$ were male and $47.88 \%(n=34)$ were female. All patients had risk factors for Brucellosis infection. These risk factors were the consumption of uncooked milk products $(88.7 \%$ of patients $(n=63)$ and consumption of uncooked meat and the anamnesis of contact with infected animals ( $11.3 \%$ of patients $(n=8)$.

The seasonal distribution of the disease was $14.08 \%$ $(n=10)$ in the autumn, $12.67 \%(n=9)$ in the winter, $33.80 \%$ $(n=24)$ in the spring, $40.84 \%(n=29)$ in the summer months (Table I). The complaints of patients were as follows; fever $85.91 \%(n=61)$, weakness $94.36 \%(n=67)$, sweating $71.83 \%$ $(n=51)$, anorexia $67.60 \%(n=48)$, knee-hip-low back pain $90.14 \%(n=64)$, abdominal pain $63.38 \%(n=45)$, weight loss $25.35 \%(n=18)$ and limb bruises $11.26 \%(n=8)$, scrotal pain $1.4 \%(n=1)$ (Table I).

The mean time from the onset of symptoms to diagnosis was 6 weeks (4-16). 78.87\% $(n=56)$ of the patients were acute and $21.12 \%(n=15)$ were subacute Brucellosis. Clinical findings were 91.54\% $(n=65)$, fever $87.32 \% \quad(n=62)$, arthritis/arthralgia 90.14\% ( $n=64)$, hepatomegaly $19.71 \%(n=14)$, splenomegaly $9.85 \%(n=7)$, petechia-purpura was $2.8 \%(n=2)$, scrotal swelling and redness $1.4 \%(n=1)$. Scrotal edema and hydrocele were detected in the ultrasonography of those patient with scrotal pain.

In the complete blood count of patients, $54.92 \%$ $(\mathrm{n}=39)$ had normal leukocyte $\left(4000-10.000 / \mathrm{mm}^{3}\right)$, $18.30 \%(n=13)$ had leukocytosis $\left(>10.000 / \mathrm{mm}^{3}\right), 26.76 \%$ $(n=19)$ had leukopenia $\left(<3500 / \mathrm{mm}^{3}\right), 36.61 \%(n=26)$ had anemia, $12.71 \%(n=9)$ had thrombocytopenia $(<150000 /$ 


\begin{tabular}{|c|c|c|}
\hline & $\mathbf{n}$ & $\%$ \\
\hline \multicolumn{3}{|l|}{ Demographic data } \\
\hline Average age & - & 7.4 \\
\hline \multicolumn{3}{|l|}{ Season } \\
\hline Fall & 10 & 14.8 \\
\hline Winter & 9 & 12.67 \\
\hline Spring & 24 & 33.8 \\
\hline Summer & 29 & 40.84 \\
\hline \multicolumn{3}{|l|}{ Gender } \\
\hline Male & 37 & 52.12 \\
\hline Female & 34 & 47.88 \\
\hline \multicolumn{3}{|l|}{ Incubation period } \\
\hline Acute & 56 & 78.87 \\
\hline Subacute & 15 & 21.12 \\
\hline \multicolumn{3}{|l|}{ Brucellosis risk factor } \\
\hline $\begin{array}{l}\text { Non pasteurized milk } \\
\text { product consumption }\end{array}$ & 63 & 88.7 \\
\hline $\begin{array}{l}\text { Consumption of raw } \\
\text { products dumplings }\end{array}$ & 8 & 11.3 \\
\hline \multicolumn{3}{|l|}{ Complaints } \\
\hline Fatigue & 67 & 94.36 \\
\hline Joint pain & 64 & 90.14 \\
\hline Fever & 61 & 85.91 \\
\hline Sweating & 51 & 71.83 \\
\hline Loss of appetite & 48 & 67.6 \\
\hline Abdominal pain & 45 & 63.38 \\
\hline Weight loss & 18 & 25.35 \\
\hline Skin finding & 8 & 11.26 \\
\hline Scrotal pain & 1 & 1.4 \\
\hline \multicolumn{3}{|l|}{ Physical examination } \\
\hline Fever & 65 & 91.54 \\
\hline Fatigue & 62 & 87.32 \\
\hline Arthritis/arthralgia & 64 & 90.14 \\
\hline Hepatomegaly & 14 & 19.71 \\
\hline Splenomegaly & 7 & 9.85 \\
\hline Petechia/purpura & 2 & 2.8 \\
\hline Scrotal swelling/redness & 1 & 1.4 \\
\hline
\end{tabular}

\begin{tabular}{|l|l|l|}
\hline \multicolumn{2}{|l|}{ Table I. Continued } & \multicolumn{2}{l|}{} & $\%$ \\
\hline Laboratory values & \multicolumn{2}{|l|}{} \\
\hline Normal leukocyte & 39 & 54.92 \\
\hline Leukocytosis & 13 & 18.30 \\
\hline Leukopenia & 19 & 26.76 \\
\hline Anemia & 26 & 36.61 \\
\hline Thrombocytopenia & 9 & 12.71 \\
\hline Severe thrombocytopenia & 2 & 2.81 \\
\hline Increased ESR & 57 & 80.28 \\
\hline CRP elevation & 59 & 83.09 \\
\hline Hematological parameters* & \\
\hline Hemoglobin & $7.6(5.2-16.1)$ & \\
\hline Leukocyte & $4.3 \times 10^{3}\left(2.7 \times 10^{3}-17.4 \times 10^{3}\right)$ \\
\hline Platelets & $152 \times 10^{3}\left(17 \times 10^{3}-165 \times 10^{3}\right)$ \\
\hline
\end{tabular}

*Mean value (minimum-maximum)

$\left.\mathrm{mm}^{3}\right), 2.81 \%(\mathrm{n}=2)$ had severe tombocytopenia $(<20000 /$ $\left.\mathrm{mm}^{3}\right)$.

It was found that $80.28 \%(n=57)$ had increased ESR and $83.09 \%(n=59)$ had CRP elevation, and $36.61 \%(n=26)$ had increased transaminase levels. None of the patients had any signs of skin complaints other than thrombocytopenic petechia-purpura. During the first evaluation of the patients, using the Wright agglutination test, $85.91 \%(n=61)$ were found to be positive.

During the initial assessment for Wright agglutination test, 10 patients were negative despite having the diagnosis of Brucellosis with complaints, family history, Brucella transmission risk factors and clinical findings. However, when repeated after one week, the Wright agglutination test on these patients were positive. Brucellosis family history was found in $52.11 \%(n=37)$ of the patients. There were no mortal complications in any of the patients.

It was determined that in anamnesis, Brucellosis was confused with variable diseases; unknown fever $7.04 \%$ $(n=5)$, leukemia $2.81 \%(n=2)$, tuberculosis $1.40 \%(n=1)$, ankylosing spondylitis $4.22 \%(n=3)$, acute rheumatic fever $1.40 \%(n=1)$, familial Mediterranean fever $4.22 \%(n=3)$, kawasaki disease $1.40 \%(n=1)$ and septic arthritis $1.40 \%$ $(n=1)$ (Table II).

In treatment; for children under eight years of age; 8 $\mathrm{mg} / \mathrm{kg}$ trimethoprim/sulfamethoxazole twice daily for six weeks and $30 \mathrm{mg} / \mathrm{kg}$ intramuscular (IM) streptomycin was administered at a single dose per day for three weeks. For 
Table II. Uncertain/confusing clinical presentations

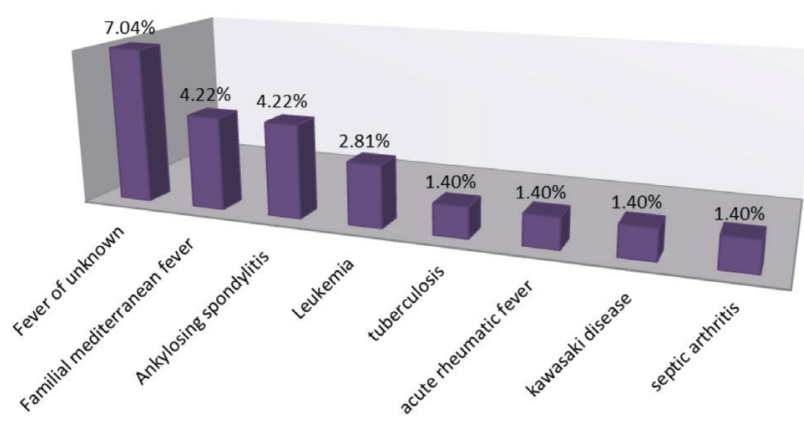

children over eight years of age; $100 \mathrm{mg}$ oral doxycycline per 12 hours for 6 weeks and $5 \mathrm{mg} / \mathrm{kg} \mathrm{IM}$ or intravenous gentamicin was administered daily for the first 7-10 days (10). Clinical improvement was observed in all patients.

\section{Discussion}

The studies concerning Brucellosis in the eastern regions of Turkey have reported that the consumption of uncooked milk and meat of infected animals were between $63 \%$ and $85 \%$ in the anamnesis of patients with Brucellosis $(10,11)$. In our study, the risk factors for Brucellosis was similar to the literature (Table I). The incidence of Brucellosis was found to be low in winter and autumn and high in summer and spring months in studies $(5,12,13)$. In our study, the seasonal distribution of the disease was found to be similar to the literature (Table I).

It is reported that there is no significant difference between gender in the incidence of Brucellosis in the literature. Although the disease can be seen in all age groups, it is more frequently seen in adolescents and young adults $(3,5,11)$. As the clinical signs and symptoms of Brucellosis are not specific, it may cause diagnostic confusion. In our country, it has been reported that the most common complaints related to Brucellosis were fever, fatigue, loss of appetite, sweating, weight loss, joint pain (knee, hip, waist), abdominal pain and headache $(3,5,14)$. Our study was similar to the literature (Table I).

In the evaluation of the patients with Brucellosis according to the duration of the symptoms, it was determined as follows; for acute cases it was between 0 to 2 months, for subacute cases it was between 2 to 12 months and for chronic Brucellosis it was above 12 months $(3,15)$. In our study, the mean time from the onset of symptoms to diagnosis was 6 weeks. $78.87 \%(n=56)$ of the patients were acute and $21.12 \%(n=15)$ of the patients were subacute Brucellosis. In our study, the absence of chronic Brucellosis cases can be associated with the early diagnosis of patients.
Neurobrucellosis is usually seen in patients with late diagnosis and it has been reported in less than $5 \%$ of all Brucellosis patients in the literature $(11,16,17)$. In our study, the absence of neurobrucellosis cases can be associated with the early diagnosis of patients who were still in the acute period of Brucellosis.

Genitourinary complications related to Brucellosis have rarely been reported as epididymo orchitis case reports. It presents with clinical symptoms in the form of scrotal pain and edema. $(12,18,19)$. Similar to the literature, in our study, genitourinary complications related to Brucellosis was detected rarely (1.4\% of patients).

Hematological and biochemical findings due to Brucellosis are not specific and not diagnostic. Indeed, they resolve with the treatment of the disease and usually does not require additional treatment (11,20-22). Similar to the literature, in our study, elevated ESR $83.09 \%(n=59)$, elevated CRP $36.21 \%(n=26)$ and elevated transaminase $80.28 \%(n=57)$ were detected (Table I).

In the literature, it has been reported that there are non-specific skin lesions such as petechiae, eczema, urticaria, papules and abscess in 0.7-17\% of Brucellosis cases $(17,23)$. In our study, findings of skin complaints were not observed other than petechia-purpura-ecchymosis due to thrombocytopenia. In our study, the absence of the skin lesion due to Brucellosis can be associated with the early diagnosis of patients who were in the acute or subacute period of Brucellosis.

Brucellosis can be confused with many diseases because it is a systemic infectious disease that can affect many organs and tissues and there are no diagnostic clinical or laboratory findings $(1,3,5)$. In this study, it was determined that Brucellosis was confused with various disease (Table II).

Diagnosis of the disease is made by the bacterial culture and Wright agglutination test $(1,3,14)$. However, bacteremia may not occur in all patients, so it is not always possible to produce bacteria $(3,12,24)$. Therefore, serological tests play an important role in the diagnosis and Wright tube agglutination test is widely used in the serological diagnosis of Brucellosis $(3,6,7,24,25)$. Polymerase chain reaction can be used for the rapid diagnosis of Brucellosis. However, it has not been routinely used because it is not standardized and it is expensive $(3,12,16)$. Serological tests should be repeated in cases in which clinical findings strongly support Brucellosis. It is recommended that all family members of patients with Brucellosis should also be examined for the disease. In the literature, it was reported that the positivity rate of family anamnesis was $54.5 \%$ in Brucellosis cases (5). Similar to 
the literature, in our study, family anamnesis (at least one person) was positive in $52.11 \%(n=37)$ of patients.

The Brucellosis can cause sometimes life-threatening complications such as spondylitis, infectious endocarditis and encephalitis. Complications usually occur due to late diagnosis and inadequate treatment $(10,14)$. The absence of mortal complications in our study may be due to the early diagnosis of patients while still in the acute or subacute periods.

It should be kept in mind that the Wright agglutination test may produce false positive or false negative results. Therefore, although the Wright agglutination test may be negative, clinical findings and anamnesis are more important for diagnosis.

\section{Study Limitations}

The limitation of this study are the absence the longterm results of Brucellosis.

\section{Conclusion}

In our country where livestock farming is widespread, there is difficulty in the diagnosis of Brucellosis infections which is still a serious public health problem because of the lack of diagnostic clinical and laboratory findings. Although the early diagnosis and response to treatment of Brucellosis are very good, unfortunately, the late diagnosis and inadequate treatment may be causes of mortality and morbidity with serious complications. Brucellosis, which is an endemic disease common in our country, should be kept in mind in the diagnosis of child patients who have complaints such as fever, weakness, weight loss and especially joint pain, who present at a family health center or emergency unit.

\section{Ethics}

Ethics Committee Approval: This study was approved by Ethics Board of Mustafa Kemal University (approval number: 08/2018).

Informed Consent: All of the parents of the patients gave their informed consent prior to their child's inclusion in the study.

Peer-review: Internally peer-reviewed.

\section{Authorship Contributions}

Surgical and Medical Practices: Ç.E., M.E.Ç., Concept: Ç.E., M.E.Ç., Design: M.E.Ç., Data Collection or Processing: Ç.E., M.E.Ç., Analysis or Interpretation: Ç.E., M.E.Ç., Literature Search: Ç.E., M.E.Ç., Writing: Ç.E., M.E.Ç.

Conflict of Interest: None of the authors had conflict of interest.
Financial Disclosure: The authors declared that this study received no financial support.

\section{References}

1. Kliegman RM, Stanton BF, St Geme JW, Schor NF. In Nelson Textbook of Pediatrics. 20th edition, Philadelphia, Elsevier 2016;1419-21.

2. TC Sağlık Bakanlığı Temel Sağıı Hizmetleri Genel Müdürlüğü Çalışma Yıllığı 2006. Ankara: Sağlık Bakanlığı, 2007.

3. 3.Young E). Brucella species, p.-I.M.G., Bennett JE, Dolin R (eds), Principles and t.e.C.L. and Practice of Infectious Diseases. 2005, New York., Principles and Practice of Infectious Diseases. 2005. p. 2669-674.

4. Bikas C, Jelastopulu E, Leotsinidis M, Kondakis X. Epidemiology of human brucellosis in a rural area of north-western Peloponnese in Greece. Eur J Epidemiol 2003;18:267-74.

5. Orduña A, Almaraz A, Prado A, et al. Evaluation of an immunocapture-agglutination test (Brucellacapt) for serodiagnosis of human brucellosis. I Clin Microbiol 2000;38:4000-5.

6. Troy SB, Rickman LS, Davis CE. Brucellosis in San Diego: Epidemiology and species-related differences in acute clinical presentations. Medicine (Baltimore) 2005;84:174-87.

7. Cockerill FR 3rd, Wilson JW, Vetter EA, et al. Optimal testing parameters for blood cultures. Clin Infect Dis 2004;38:172430.

8. Palanduz A, Palanduz S, Güler K, Güler N. Brucellosis in a mother and her young infant: probable transmission by breast milk. Int J Infect Dis 2000;4:55-6.

9. Çelebi S, Hacımustafaoğlu M, Yılmaz E. Çocuklarda nörobruselloz: üç vaka takdimi. Cocuk Sağlığı ve Hastalıkları Dergisi 2004;47:46-9.

10. Pickering LK, Baker C), Long SS, McMillan JA (eds). Red Book. 28th edition. Elk Grove Village, IL: American Academy of Pediatrics; 2009.p.235-7.

11. Gur A, Geyik MF, Dikici B et al. Complications of brucellosis in different age groups: a study of 283 cases in southeastern Anatolia of Turkey. Yonsei Med I 2003;44:33-44.

12. Tanir G, Tufekci SB, Tuygun N. Presentation, complications, and treatment outcome of brucellosis in Turkish children. Pediatr Int 2009;51:114-9.

13. Buzgan T, Karahocagil MK, Irmak H et al. Clinical manifestations and complications in 1028 cases of brucellosis: A retrospective evaluation and review of the literature. Int I Infect Dis 2010;14:469-78

14. Solera J, Lozano E, Martinez-Alfaro E, Espinosa A, Castillejos ML, Abad L. Brucellar spondylitis: Review of 35 cases and literature survey. Clin Infect Dis 1999;29:1440-9.

15. Boschiroli ML, Foulongne $\mathrm{V}, \mathrm{O}^{\prime}$ Callaghan D. Brucellosis: $A$ worldwide zoonosis. Curr Opin Microbiol 2001;4:58-64.

16. Karadağ-Öncel $E$, Özsürekci $Y$, Cengiz $A B$, et al. Çocukluk çağında bruselloz: Hacettepe Üniversitesi deneyimi. Çocuk Sağlığı ve Hastalıkları Dergisi 2011;54:135-41.

17. Hizel K, Guzel O, Dizbay M, et al. Age and duration of disease as factors affecting clinical findings and sacroiliitis in brucellosis. Infection 2007;35:434-7. 
18. Bayram Y, Korkoca H, Aypak C, et al. Antimicrobial susceptibilities of Brucella isolates from various clinical speciemens. Int I Med Sci 2011;8:198-202.

19. Navarro-MartínezA, SoleraJ, Corredoira), etal. Epididymoorchitis due to Brucella mellitensis: A retrospective study of 59 patients. Clin Infect Dis 2001;33:2017-22.

20. Al Dahouk S1, Tomaso H, Nöckler K, Neubauer H, Frangoulidis D. Laboratory-based diagnosis of brucellosis--a review of the literature. Part II: serological tests for brucellosis. Clin Lab 2003;49:577-89.

21. Starakis I, Mazokopakis EE, Bassaris H. Unusual manifestations of brucellosis: A retrospective case series in a tertiary care Greek university hospital. East Mediterr Health I 2010;16:365-70.
22. Bosilkovski M, Krteva L, Dimzova M Kondova I. Brucellosis in 418 patients from the Balkan Peninsula: Exposure-related differences in clinical manifestations, laboratory test results, and therapy outcome. Int I infect Dis 2007;11:342-7.

23. Gül HC, Coşun Ö, Turhan V, et al., Bruselloz: 140 olgunun geriye dönük olarak irdelenmesi. TSK Koruyucu Hekimlik Bülteni, 2007;6:249-52.

24. Gotuzzo E, Bocanegra TS, Alarcon CS, Carrillo C, Espinoza LR. Humoral immune abnormalities in human brucellosis. Allergol Immunopathol 1985;13:417-24.

25. Kutlu SS, Çelikbaş $A$, Ergönül $O$, et al. The value of the immunoglobulin $G$ avidity test for the serologic diagnosis of brucellosis. Mikrobiyol Bul 2003;37:261-7. 